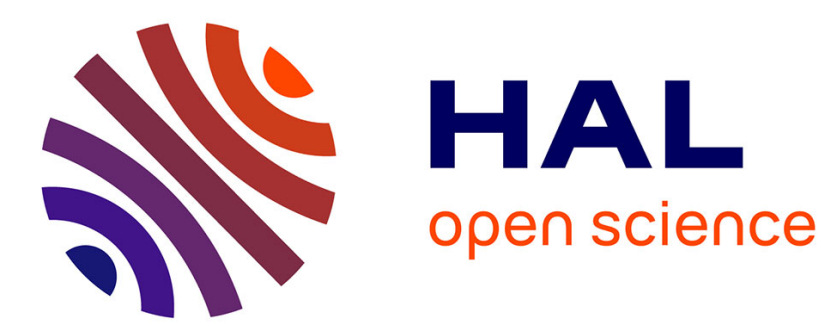

\title{
ATOM PROBE MICROANALYSIS OF THE METALLIC GLASSES
}

\author{
Z. Liu, Y. Chen, X. Wu
}

\section{To cite this version:}

Z. Liu, Y. Chen, X. Wu. ATOM PROBE MICROANALYSIS OF THE METALLIC GLASSES. Journal de Physique Colloques, 1988, 49 (C6), pp.C6-317-C6-322. 10.1051/jphyscol:1988655 . jpa00228152

\section{HAL Id: jpa-00228152 https://hal.science/jpa-00228152}

Submitted on 1 Jan 1988

HAL is a multi-disciplinary open access archive for the deposit and dissemination of scientific research documents, whether they are published or not. The documents may come from teaching and research institutions in France or abroad, or from public or private research centers.
L'archive ouverte pluridisciplinaire HAL, est destinée au dépôt et à la diffusion de documents scientifiques de niveau recherche, publiés ou non, émanant des établissements d'enseignement et de recherche français ou étrangers, des laboratoires publics ou privés. 
The Laboratory of Solid State Microstructures, Nanjing University. Nanjing, People's Republic of China

*Institute of Solid State Physics, Academia sinica,

People's Republic of China

\begin{abstract}
The chemical inhomogeneities over the order of nanometers in two transition metal-metalloid amorphous alloys have been investigated by means of atom probe field ion microscopy (APFIM). In as quenched Feg2.3 Nil.7 B 16 glass the existence of two amorphous phases with different boron concentrations was revealed. The mean size of the precipitated (FeNi) 3 B-phase was determined to be about 3 nanometers. The interface between the two phases seems to be rather distict. However, in as quenched or at $350^{\circ} \mathrm{C}$ for an hour annealed Fe80.7 $\mathrm{B}_{12.8} \mathrm{Si}_{3.9} \mathrm{C}_{2.6}-\mathrm{glas8}$, no regions depleted or enriched in one component detectable can be found. In annealing the glass kept homogeneous on the scale of nanometer, although the specimen underwent a ductile-brittle transition. It wag concluded that in this metallic glass phase separation is not involved in the annealing embrittlement.
\end{abstract}

\title{
I. Introduction:
}

It has become clear in recent years that some sort of inhomoseneities must be influencing many of the properties of the metallic glasses such as the magnetic properties, superconductivity and ductility. Up to now extensive informations on nearest nighbours have been accumulated by Moessbauer spectra (1), NMR (2), EXSAFS (3) et al. However, less information concerning the chemical inhomogeneities in the range of several angstroms to $10 \mathrm{~nm}$ has been reported. Atom probe field ion microgcopy ( APFIM) has been proved to be very useful in studying the concentration fluctuation and phase separation in glassy metals, because this method has the advantage that it allows the local composition of the area as amall as several anstroms in diameter to be determined in quantitative manner. This method has been succesafully applied to the investigation of amorphous alloys $\mathrm{Fe}_{40} \mathrm{Ni} \mathrm{i}_{40} \mathrm{~B}_{20}(4), \mathrm{Ti}_{50} \mathrm{Be}_{40} \mathrm{Zr}_{10}(5)$ and $\mathrm{Pd}_{84} \mathrm{~S} \mathrm{i}_{16}(6)$.

In the present work APFIM investigations were performed to examine the chemical inhomogeneity and phase seperation in the transition metal-metalloid glasses $\mathrm{Fe}_{82.3} \mathrm{Ni}_{1.7} \mathrm{~B}_{16}$ and $\mathrm{Fe}_{80.7} \mathrm{~B}_{12.8} \mathrm{Si}_{3.9} \mathrm{C}_{2.6}$ respectively.

\section{Experimental procedure:}

The amorphous alloys $\mathrm{Fe}_{82.3} \mathrm{Ni}_{1.7} \mathrm{~B}_{16}$ and $\mathrm{Fe}_{80.7} \mathrm{~B}_{12.8} \mathrm{Si}_{3.9} \mathrm{C}_{2.6}$ were prepared from high purity materials by a single gide drum technique. Long ribbons about $10 \mu \mathrm{m}$ thick 1 $\mathrm{mm}$ wide and about $25 \mu \mathrm{m}$ thick $8 \mathrm{~mm}$ wide were obtained respectively. No indication of crystallization in the specimens can be detected by large angle $X-r a y$ diffraction meagurement, in which the first and second halo peaks were observed which is usually recognized to be an indication of the amorphous state. The ribbons were first ground from the side until an approximately square cross section was obtained. Some of the ground ribbons of Fego.7 $\mathrm{B}_{12.8} \mathrm{Si}_{3.9} \mathrm{C}_{2.6}$ were then encapsulated in a glass tube which has been evacuated to a pressure $10^{-4}$ Pa and backfilled with high purity argon and isothermally annealed at $350^{\circ} \mathrm{C}$ for an hour. The annealed specimen was tested by $X$-ray diffraction measurement. Again, no crystalline state can be detected. The FIM tips of all materials were prepared by electrochemical polishing in a mixture of $30 \mathrm{ml}$ perchloric acid, 10 ml acetic acid and $60 \mathrm{ml}$ ethylene slycol monobutyl ether at 8-20 VDC. 
The APFIM investigations were performed in the instrument of Nanjing University, which hag been described in detail elsewhere (7). The tipg were inaged at a temperature of $85 \mathrm{~K}$, using neon as imaging gas at a pressure of $7 * 10^{-3} \mathrm{~Pa}$. In order to prevent preferential evaporation effect from interfering, a high puleses fraction ( $20 \%-22 \%)$ was used. In addition, the averaged number of pulsea per collected ion was kept greater than 50 so as to minimize ion pile-up artifacts. On these conditions, the determined chenical compositions of the glasses are in agreement with their nominal compositions.

To tegt the homogeneity of the metallic glagses, the concentration profiles of each component along a cylinder with a diameter of about $2 \mathrm{~nm}$ were determined layer by layer. Exactly speaking, "atomic layer " is meaningful only for crystalline specimen. One "atomic layer" is defined here by collecting 40 ions ( hydrogen ions are excluded) and corresponds to a thickness of about $0.2 \mathrm{~nm}$. Due to the small number of atoms collected from each layer the statistical fluctuation is so large that it is difficult to determine the true size and composition of the areas enriched in some elements. For this reason the concentration profiles were analysed by the statistical method of autocorrelation $(8,9)$, which is calculated acording to the formula:

$$
R(K)=\frac{n}{(n-K)} \sum_{i=1}^{n-k}\left(c_{i}-c_{0}\right)\left(c_{i+k}-c_{0}\right) / \sum_{i=1}^{n}\left(c_{i}-c_{0}\right)^{2}
$$

$c_{i}$ being the concentration of an element in $i-t h$ evaporated layer; $c_{0}$ the mean concentration of the element in the specimen; $n$ the total number of evaporated layers; $K$ the correlation length in unit of interlayer distance.

III. Results and discussion:

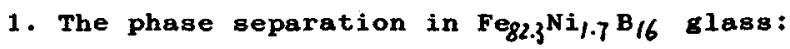

The neon field ion image of an as quenched apecimen is shown in figure 1. The image spots are irregularly distributed. This implies that there is no $10 \mathrm{~s}$ range ordering in the structure. It can be seen in figure 1 that there geems to be two kinds of spots i.e. the bigger spotg and the smaller ones. Since the atom probe analysis revealed that the metal ions evaporate preferentially, we suess the bigger spots corresponding to boron atoms. Some efforts have been made to check the correspondence between the appearence of the spots and the atons of different elements. Unfortunately, one to one correspondence has not been achieved. However, it follows that most of the bigger spots are due to boron atoma This is in agreement with the observation of Piller and Hasen (4).

To investigate the composition fluctuation in the material, atom probe random area analysis was performed. Figure 2 a) shows the concentration profile of boron and iron, in which small excursion from statistical scatter about the mean composition can be observed. The concentration profileswere than analysed by autocorrelation as shown in equation 1 . In figure 2 b) the autocorrelation $R(k)$ for the boron concentration profile shown in figure 2 a) is plotted versus the layer spacing $h$, from which the mean size of the boron rich area was determined to be about $3 \mathrm{~nm}$. The size of the boron-rich regions was believed to be large enough to ensure these regions as well-defined independent second amorphous phase. The compositions of the precipitated boron-rich phase and the boron-depleted iatrix were estimated to be $(\mathrm{Fe}, \mathrm{Ni})_{3} \mathrm{~B}$ and (FeNi) $)_{6} \mathrm{~B}_{14}$ respectively.

Some hydrogen dissolved in the material was detected by atom probe, although the specimen was outgased for more than 12 hours before the invegtigation started. The integral concentration profile of hydrogen wag ghown in figure 3 together with that of boron. It is very interesting to note that the distribution of hydrogen is not homogeneous. The hydrogen concentration in boron-rich phase was found to be much lower than that in boron-depleted phase. This is another evidence confirming that the phase seperation has realy occured in the specimen. Furthermore, it can be seen that the boundary between the two amorphous phases are probably fairly distinct.

\section{The chemical homogeneity of $\mathrm{Fe}_{80.7} \mathrm{~B}_{12.8} \mathrm{Si}_{39} \mathrm{C}_{2.6} \mathrm{glags}$}

The metallic glass $\mathrm{Fe}_{80.7} \mathrm{~B}_{12.8} \mathrm{Si}_{3.9} \mathrm{C}_{2.6}$ and some glasses quite cloge in conposition to the present one undergo a transition from the ductile state to brittle state when annealed at temperature well below the crystallization temperature. However, 
the processes which are involved in the annealing embrittlement are not yet understood and quite different explanations have been proposed up to now (10): phase separation in the slasses, local enrichment of one component, reduction of free volume or onset of crystallization at the surface. To test whether these explanations to be true, more experimental verifications of the defects and inhomogeneities, especialy the chemical inhomogeneities in the slassy specimens before and after ductile-brittle transition are needed. For this purpose two

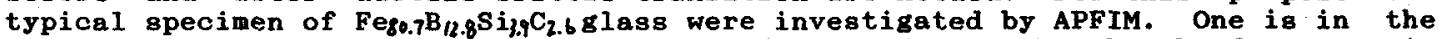
as-quenched melt spun state and was tested to be ductile by the bend test, in which the strip was bent into a U-shape and slowly brought together untill the fracture occured. Another specimen was annealed isothermally at $350^{\circ} \mathrm{C}$ for 1 hour and was found to be very brittle.

The field ion images of the two specimens are very similar. The micrograph taken frow the annealed specimen was shown in figure 4. Again, the image spots distributed randomly, neither long range ordering nor image contrast indicating different phases can be observed. Like in the images of Feg2.3 Ni/.7 B/6 and other amorphous materials, the abundance of the image spots is markly lower than for crystalline materials. The reason of which was believed to be the random distribution and the irregular field evaporation behaviour of the surface atoms in the amorphous materials resulting a thinner effective Moore shell (11).

Figure 5 shows the mass spectrum of the as quenched specimen taken by atom probe. The carbon was found to be remarkablly lower than 2.6\%. This discrepancy was thought to be due to the complex charged state and the occurence of carbon cluster ions which made it very difficult to resolve all carbon atoms in the atom probe data.

The concentration profiles obtained by atom probe from the annealed glass were ghown in figure 6 , in which no any indication of two phase microstructures can be found. A more detailed and reliable examination of the concentration fluctuation was obtained by analyzing the concentration profiles by autocorrelation analysis method. Figure 7 . shows the correlogram of the Fe-,B-,Siconcentration profile of figure 6. The correlation coefficients for the three elements drop to zero already for $K=1$. This indicates that the alloy does not have any fine precipitates detectable by atom probe random area analyaia. The atom probe analysis was also performed to investigate the as quenched specimen. The same results were obtained. The specimen was found to be homogeneous on the scale of nanometer.

Based on their APFIM investigation of Fe $40 \mathrm{Ni}_{40} \mathrm{~B}_{20}$, Piller and Haasen concluded that the ductile-brittle transition takes place when the mean size of (FeNi) 3 Bprecipitates becomes larger than $30 \mathrm{~nm}$ during annealing. However, from the results of the present work, it can be concluded that in $\mathrm{Fe}_{80.7} \mathrm{~B}_{12.8} \mathrm{Si}_{3.9} \mathrm{C}_{2.6} \mathrm{glass}$ phase separation and local enrichment of one component are not involved in the annealing embrittlement. Some different hypotheses in which chemical inhomogeneity is not involved have been proposed. Argon (12), on the basis of his comprehensive soapbubble simulations, attributes thermal embrittlement to an alteration in the distribution of free volume. Gerling et al. (13) conclude that thermal embrittlement is due to a critical degree of cluster formation or a critical reduction in free volume. Obviously, to understand the embrittlement mechanism of matallic glasses unequivocally, further experimental works are needed.

Acknowledgment: The authors would like to thank Prof. D.Feng for atimulating discussion. We also wish to thank $X$,Y.Qin and $X$. Wu for experimental assigtance. The project was supported by the National Natural scientific Foundation of China.

\section{Literature:}

(1) I.Vincze and F.Van der Woude. J. Non-cryst. Solids 42499 (1980)

(2) J. Durand and M. F. Lapierre, J. Phys. F 61185 (1976)

(3) S. J. Gurman, J. Mater. Sci. 171541 (1982)

(4) J. Piller and P. Haasen. Acta Met. 301 (1982)

(5) R. Gruene, M. Oehring, R. Wagner and P. Haasen, in: "Rapidly Quenched Metals" Eds: $S$. Steeb and $H$. Warlimont, Elsevier, P761 (1985)

(6) M. Yamamoto, H. Yao, S. Nenno, I. Ohnaka and T. Fukusako, J. de Physique C6, 311 (1987)

(7) Z. G. Liu, Y. N. Cao and D. Feng, J. de Physique C6, 343 (1987) 
(8) M. Kendall, Time Series, 2nd Edn, Griffin, London (1976)

(9) J. Piller and $\mathrm{H}$. Wendt, Proc, 29 th Int. Field Fmission Symp. Bds. H-O. Andren and H. Norden, Goeteborg, P265 (1982)

(10) P. Lamparter, D. M. Kroeger and S. Spooner, Scripta Met. 21715 (1987)

(11) H. B. Elswijk, P. M. Bronsveld and J. Th. M. De Hooson, J. de Physique C6, $305(1987)$

(12) A. S. Argon, J. Phys. Chem. Solids 43945 (1982)

(13) R. Gerling, F. P. Schimangky and R. Wagner, Scripta Met. 17203 (1983)

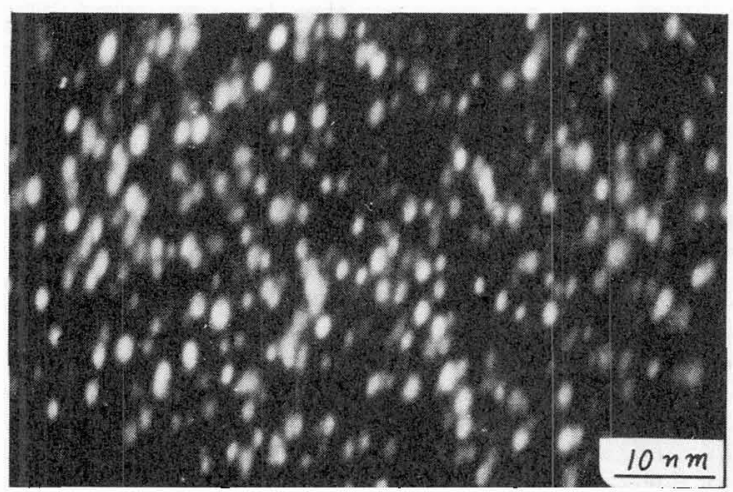

Figure 1. Neon field ion image of an as quanched amorphous Fe $82.3 \mathrm{Ni}, 7 \mathrm{~B} / 6$ specimen at $7 \mathrm{kV}$ and $85 \mathrm{~K}$.

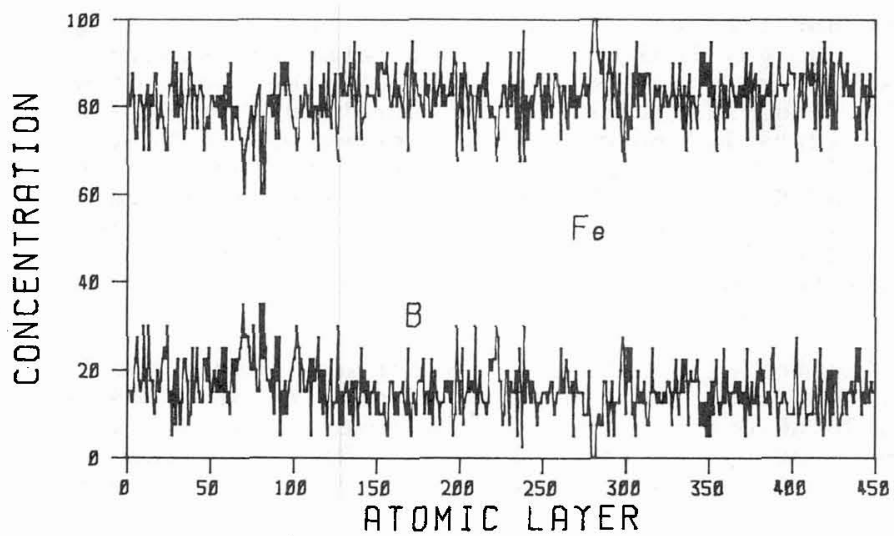

a)

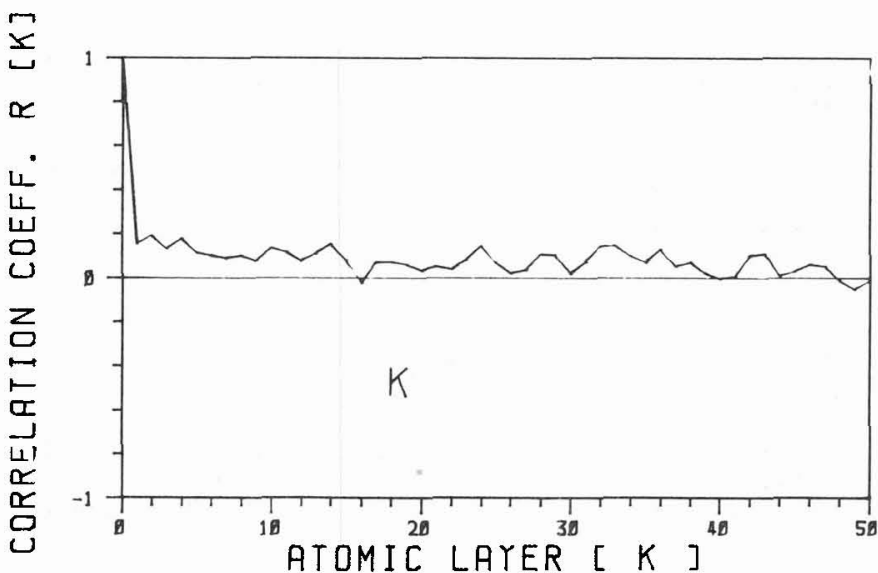

Figure 2. a) Fe- and Bconcentration profile of the as quenched Fe82.3 $\mathrm{Ni}_{1.7} \mathrm{~B} / 6$ glass. b) Autocorrelation $R(k)$ of the boron concentration profile shown in a). 

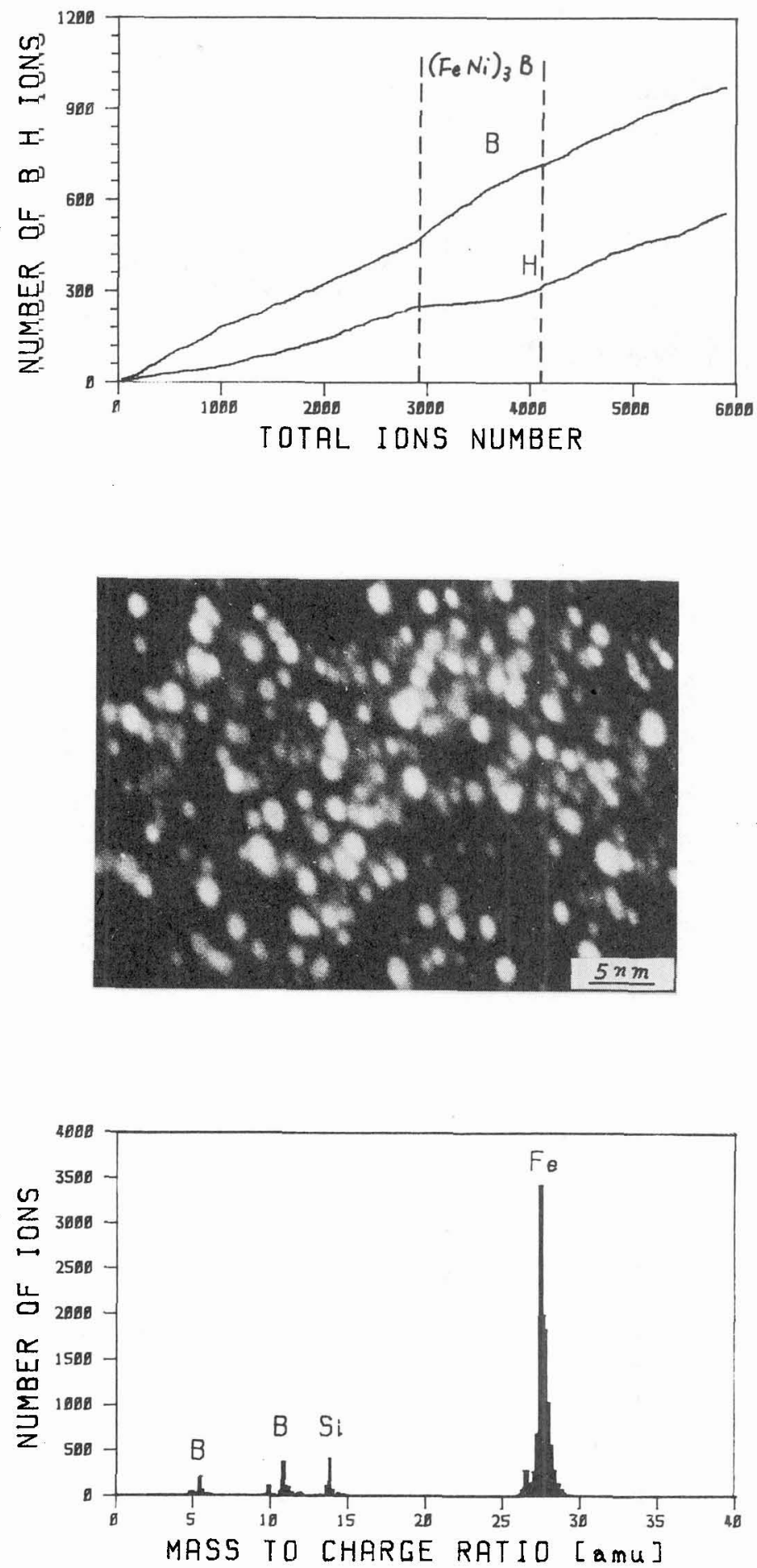

Figure 3 . Integral concentration depth profile of $B$ and $H$ in as quenched Feg2.3 Ni $/ .7 \mathrm{~B} / 6$ glass. The H-concentration in B-enriched phase is lower.
Figure 4. Neon field ion image of a Fe 80.7 $\mathrm{B}_{12.8} \mathrm{Si}_{3.9} \mathrm{C}_{2.6}$ specimen annealed at $350^{\circ} \mathrm{C}$ for 1 hour.
Figure 5. Mass histogram of the as quenched $\mathrm{Fe}_{80.7} \mathrm{~B}_{12.8} \mathrm{Si}_{3.9} \mathrm{C}_{2.6}$ glass taken by atom probe. 


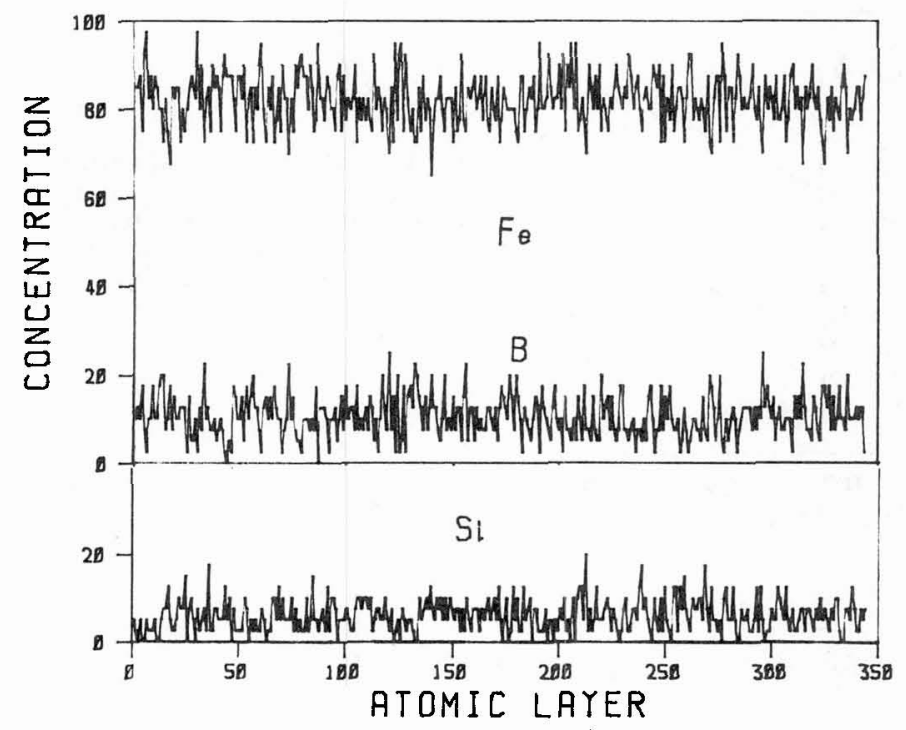

Figure 6. The concentration

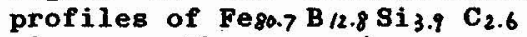
glas8. The specimen was annealed at $350^{\circ} \mathrm{C}$ for an hour. No phase separation can be detected.
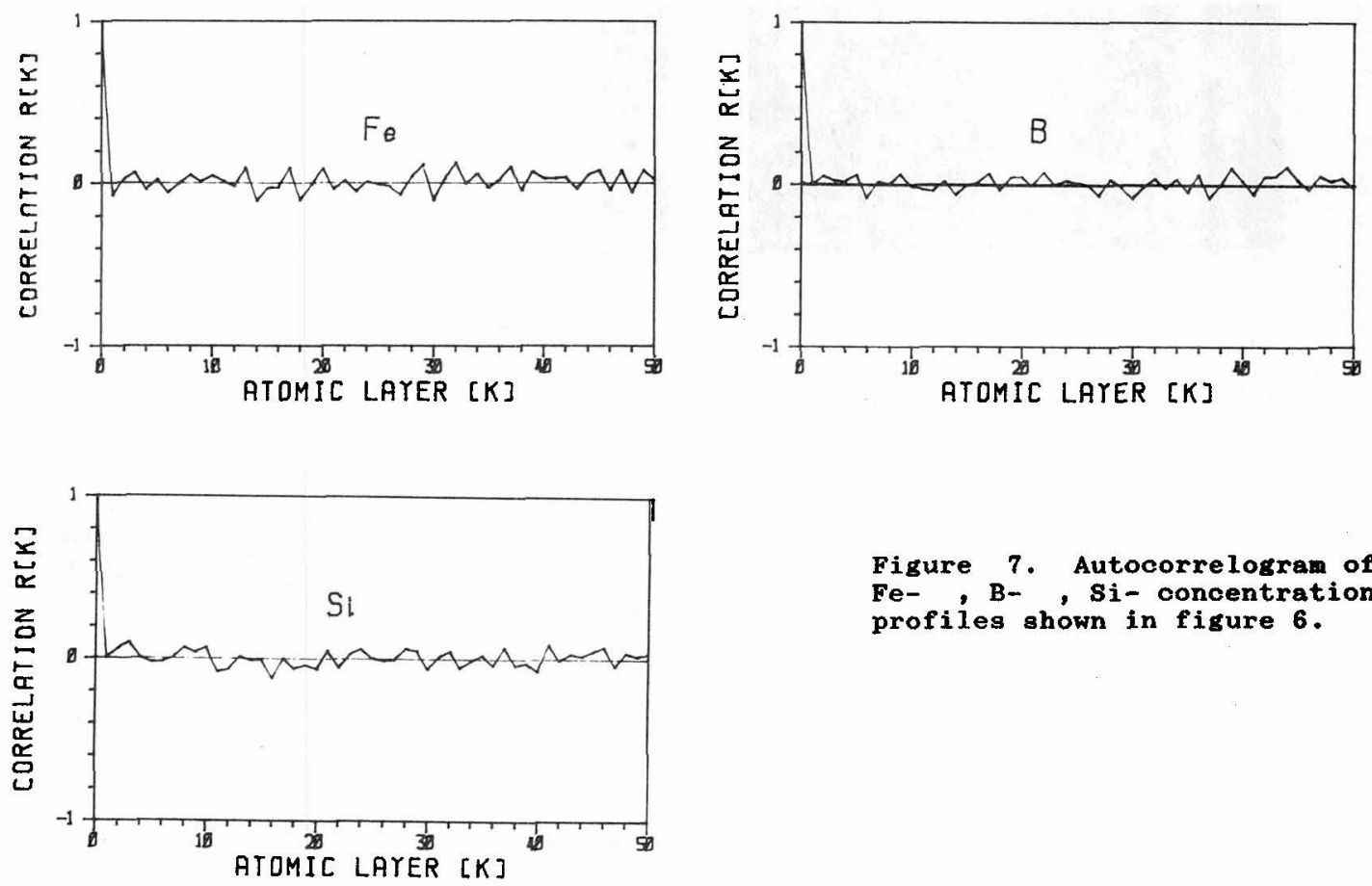

Figure 7. Autocorrelogram of Fe- , B- , Si- concentration profiles shown in figure 6 . 